\title{
Nested-PCR do gene que codifica o antígeno b aplicada ao diagnóstico da tuberculose pulmonar
}

\author{
Nested-PCR for gene that encodes the antigen b applied \\ to the diagnosis of pulmonary tuberculosis
}

\author{
Karla Valéria Batista Lima1, Maria Luíza Lopes', Edvaldo Carlos Brito Loureiro', \\ Maurimélia Mesquita Costa ${ }^{1}$, Ninarosa Calzavara Cardoso ${ }^{2}$, \\ George Leandro Ferreira Lima ${ }^{3}$ e Maísa Silva Sousa ${ }^{4}$
}

\begin{abstract}
RESUMO
A reação em cadeia da polimerase usada para amplificação de uma seqüência interna de um fragmento previamente amplificado (nested-PCR) foi investigada como uma alternativa complementar a pesquisa de bacilos álcool ácido resistentes e a cultura do Mycobacterium tuberculosis em meio de Lowenstein-Jensen. Foram investigadas 144 amostras de escarro de pacientes suspeitos de tuberculose encaminhados ao Laboratório de Tuberculose do Instituto Evandro Chagas em Belém, no período de junbo de 2002 a dezembro de 2003. Das 144 amostras, 121 foram caracterizadas como tuberculose, 119 foram positivas na cultura, 95 na baciloscopia e 128 na nested-PCR. A sensibilidade da nested-PCR foi 96\% (116/121), enquanto a especificidade foi 48\% (11/23). A nested-PCR poderá ser uma ferramenta complementar para o diagnóstico da tuberculose, pois apresenta sensibilidade equivalente à cultura, no entanto, necessita de maiores avaliações visando minimizar o número de resultados falso-positivos.
\end{abstract}

Palavras-chaves: Tuberculose. Nested-PCR. Mycobacterium tuberculosis. Diagnóstico molecular. Antígeno b.

\begin{abstract}
The polymerase chain reaction used for amplifying an internal sequence of a previously amplified fragment (nested-PCR) was investigated as a complementary alternative for searching for alcohol-acid resistant bacilli and Mycobacterium tuberculosis cultures in Lowenstein-Jensen medium. 144 sputum samples were investigated from patients with suspected tuberculosis that were sent to the Tuberculosis Laboratory of the Evandro Chagas Institute in Belém, between June 2002 and December 2003. From the 144 samples, 121 were characterized as tuberculosis: 119 were positive in cultures, 95 under bacilloscopy and 128 using nested-PCR. The sensibility of the nested-PCR was 96\% (116/121), while the specificity was 48\% (11/23). Nested-PCR may be a complementary tool for diagnosing tuberculosis, since it presents sensitivity equivalent to that of cultures. However, further evaluations are needed with the aim of minimizing the number of false-positive results.
\end{abstract}

Key-words: Tuberculosis. Nested-PCR. Mycobacterium tuberculosis. Molecular diagnosis. Antigen b.

A incidência de tuberculose pulmonar, no Brasil, mantémse crescente, com $50 \%$ dos casos relatados como bacilíferos ${ }^{8}$. Trata-se de uma doença infecto-contagiosa de transmissão aerógena, com sintomas semelhantes a uma variedade de doenças respiratórias, o que resulta em marcante impacto no programa nacional de controle da tuberculose. Outro fator contribuinte para o agravo da doença é o número crescente de cepas de Mycobacterium tuberculosis resistentes aos tuberculostáticos recomendados pelo Ministério da Saúde do Brasil. Em Belém, capital do Pará, foi relatado $12 \%$ de resistência primária entre pacientes atendidos em uma Unidade de referência municipal para tratamento de tuberculose ${ }^{6}$.

0 método de diagnóstico da tuberculose mais difundido no Brasil é a pesquisa de bacilo álcool ácido resistente- BAAR. Tratase de um procedimento rápido e barato, no entanto, apresenta baixa sensibilidade. A cultura para oMycobacterium tuberculosis é considerada o método padrão ouro para o diagnóstico, apresenta positividade nos espécimes que contenham de 10 a 100 bacilos viáveis, no entanto, requer um período de três a oito semanas para liberação do resultado ${ }^{3}$.

1. Instituto Evandro Chagas, Belém, PA. 2. Centro de Saúde Escola do Marco, Belém, PA. 3. Laboratório Central do Pará, Belém, PA. 4. Universidade Federal do Pará, Belém, PA. Órgão Financiador: FUNTEC/ SECTAM

Endereço para correspondência: Dra. Karla Valéria Batista Lima. Rodovia 316, Km 07, Bairro Levilândia, 67030-000 Ananindeua, PA.

Tel: 5591 3214-2116; Fax: $55913214-2114$

e-mail: karlalima@iec.pa.gov.br

Recebido em 17/07/06

Aceito em 2/4/2007 
A reação em cadeia da polimerase (PCR) vem sendo investigada como alternativa de alta sensibilidade e especificidade para 0 diagnóstico rápido de doenças infecciosas como a tuberculose ${ }^{112}$. A nested-PCR, constituída por duas amplificações sucessivas do marcador molecular, é defendida por conciliar ainda maior sensibilidade e especificidade ${ }^{79}$. Este trabalho propõe avaliar a aplicabilidade da nested-PCR do gene que codifica 0 antígeno $b$ para o diagnóstico da tuberculose.

\section{MATERIAL E MÉTODOS}

Amostragem e critérios para definição de caso. Foram investigados 144 pacientes suspeitos de tuberculose encaminhados a partir do Centro de Saúde Escola do Marco (CSEM) ao Laboratório de Tuberculose do IEC, no período de junho 2002 a dezembro de 2003. 0 CSEM é uma Unidade de Saúde Pública incorporada a Universidade Estadual do Pará que funciona como referencia municipal e estadual para tuberculose.

0 critério para definição de caso de tuberculose foi 0 isolamento micobacteriano por cultivo ou a melhora clínica após introdução da terapia para casos sintomáticos com cultura negativa. Os resultados da nested-PCR não interferiram no diagnóstico da tuberculose.

Coleta, conservação e transporte do material. 0 escarro foi colhido ao despertar e encaminhado a CSEM pelo paciente ou responsável. 0 espécime foi conservado sob refrigeração a $4^{\circ} \mathrm{C}$ até 0 momento do tratamento laboratorial.

Preparação da amostra e obtenção do DNA. O escarro passou por fluidificação com n-acetil cisteína (1:1) e o precipitado obtido foi tratado com 100 $\mu \mathrm{L}$ de tampão de lise (Tris HCl pH 9,0 300mM, EDTA 100mM, sucrose 4,8\%, SDS 1,25\%), 100 $\mu \mathrm{L}$ de tampão de homogeneização (Tris $\mathrm{HCl}$ pH8 10mM, NaCl 60mM, EDTA pH8 10mM, sucrose $5 \%$ ) e $5 \mu \mathrm{L}$ de proteinase $\mathrm{K}(20 \mathrm{mg} / \mathrm{mL}$ de água ultrapura), então, incubados $56^{\circ} \mathrm{C}$ por 12 horas. Os detritos celulares e outros foram removidos por tratamento com $200 \mu \mathrm{L}$ de solução de fenol-clorofórmio-álcool isoamil (25:24:1). O DNA foi precipitado com $30 \mu \mathrm{L}$ de acetato de sódio (3M, pH 4,8) e $150 \mu \mathrm{L}$ de isopropanol, centrifugado a $12.000 \mathrm{rpm}$ e tratado com $500 \mu \mathrm{L}$ de álcool etílico $70 \%$, centrifugado a $12.000 \mathrm{rpm}, 4^{\circ} \mathrm{C} .0$ álcool foi, então, removido por evaporação e o DNA eluído em $100 \mu \mathrm{L}$ de tampão EDTA.

Nested-PCR. Os iniciadores utilizados na reação: TB1 5'-ACCACCGAGCGGTTCGCCTGA-3', TB2 5'GATCTGCGGGTCGTCCCAGGT-3' (primeira reação) e TB3 5'TGACGTTGGCGGAGACCG-3', TB4 5'- ATGGTGCCCTGGTACATG-3' amplificaram um fragmento de $322 \mathrm{pb}$ do gene que codifica uma proteína de 38-kDa, chamada antígeno b, presente em cepas do Complexo M. tuberculosis ${ }^{9}$. Cada $25 \mu \mathrm{L}$ da solução de reação para a PCR foi preparada usando tampão da enzima Taq DNA polimerase 1X (Invitrogen), 1,5mM de $\mathrm{MgCl}_{2}$ (Invitrogen), $0,4 \mathrm{mM}$ de cada deoxinucleotídeo (Invitrogen), 20pmol de cada iniciador, 0,5U da enzima Taq DNA polimerase (Invitrogen) e 40ng do DNA alvo. A reação foi então submetida a ciclos de $94^{\circ} \mathrm{C}, 63^{\circ} \mathrm{C} \mathrm{e} 72^{\circ} \mathrm{C}$, um minuto cada, em termociclador Hyband PX2. 0 produto final da PCR foi visualizado em gel de agarose 1\% após tratamento com brometo de etídio na concentração de $1 \mu \mathrm{g} / \mathrm{mL}$. A cepa de referência MT14323 foi usada para a otimização dos parâmetros da reação e como controle positivo.

Baciloscopia e cultivo micobacteriano. A baciloscopia foi realizada pelo método de Ziehl-Neelsen. Para o cultivo foi realizado tratamento do escarro pelo método do lauril sulfato de sódio e $0,1 \mathrm{~mL}$ do sedimento foi semeado em meio LowensteinJensen e incubado a $37^{\circ} \mathrm{C}$ por até 8 semanas ${ }^{3}$.

Precauções éticas. 0 projeto de pesquisa que deu origem ao presente trabalho, foi aprovado pelo Comitê de Ética em Pesquisa do Instituto Evandro Chagas em 09/07/02.

\section{RESULTADOS}

De acordo com os critérios anteriormente estabelecidos, das 144 amostras encaminhadas para diagnóstico, 121 casos foram caracterizados como provenientes de indivíduos com tuberculose, enquanto 23 foram consideradas negativas. A cultura foi positiva em 119 amostras, destas 95 foram positivas para BAAR. A nested-PCR foi positiva em 128 amostras. A relação entre os resultados obtidos na cultura, baciloscopia e nested-PCR são apresentados na Tabela 1. As 119 cepas obtidas por cultivo apresentaram sensibilidade ao ácido p-nitrobenzóico $(500 \mu \mathrm{g} / \mathrm{mL})$ e resistência a hidrazida do ácido tiofeno-2-carboxílico $(2 \mu \mathrm{L} / \mathrm{mL})$, característicos dos membros do Complexo $M$. tuberculosis e da espécie $M$. tuberculosis respectivamente.

A sensibilidade e especificidade de cada técnica são apresentadas na Tabela 2 .

Tabela 1 - Relação entre os casos diagnosticados como tuberculose e os dados obtidos por baciloscopia, cultura e nested-PCR.

\begin{tabular}{|c|c|c|c|c|c|}
\hline & \multicolumn{2}{|c|}{ Cultura positiva } & \multicolumn{2}{|c|}{ Cultura negativa } & \multirow[b]{2}{*}{ Total } \\
\hline & $\begin{array}{c}\text { BAAR } \\
\text { positivo }\end{array}$ & $\begin{array}{c}\text { BAAR } \\
\text { negativo }\end{array}$ & $\begin{array}{c}\text { BAAR } \\
\text { positivo }\end{array}$ & $\begin{array}{c}\text { BAAR } \\
\text { negativo }\end{array}$ & \\
\hline Nested-PCR positivo & 93 & 21 & $2^{*}$ & 12 & 128 \\
\hline Nested-PCR negativo & 2 & 3 & 0 & 11 & 16 \\
\hline Casos investigados & 95 & 24 & 2 & 23 & 144 \\
\hline Casos de tuberculose & 95 & 24 & 2 & 0 & 121 \\
\hline
\end{tabular}

* Em um caso foi detectado crescimento de MNT, em outro caso houve contaminação da cultura por fungo, impossibilitando a conclusão do diagnóstico por cultivo. BAAR: bacilo álcool-ácido resistente

Tabela 2 - Valores de sensibilidade, especificidade, falso positivo e falso negativo, para 144 amostras de escarro analisadas, considerando 121 casos confirmados de tuberculose.

\begin{tabular}{|c|c|c|c|c|c|c|}
\hline & \multicolumn{2}{|c|}{$\begin{array}{c}\text { Sensibilidade* } \\
\quad(n=121)\end{array}$} & \multicolumn{2}{|c|}{$\begin{array}{c}\text { Especificidade }^{* *} \\
\quad(\mathrm{n}=23)\end{array}$} & \multirow[t]{2}{*}{$\begin{array}{c}\text { Falso } \\
\text { positivo }\end{array}$} & \multirow[t]{2}{*}{$\begin{array}{c}\text { Falso } \\
\text { negativo }\end{array}$} \\
\hline & $\mathrm{n}^{0}$ & $\%$ & $\mathrm{n}^{0}$ & $\%$ & & \\
\hline Nested-PCR & 116 & 95,9 & 11 & 47,8 & 12 & 5 \\
\hline Baciloscopia & 95 & 78,5 & 22 & 95,7 & 1 & 26 \\
\hline Cultura & 119 & 98,3 & 23 & 100,0 & 0 & 2 \\
\hline
\end{tabular}

*A sensibilidade foi calculada segundo a fórmula: A/ $(\mathrm{A}+\mathrm{C}) \mathrm{x} 100$, sendo A o número de infectados detectados pelo teste e $(\mathrm{A}+\mathrm{C})$ o total de doentes.

**A especificidade foi calculada segundo a fórmula: $\mathrm{B} /(\mathrm{B}+\mathrm{D}) \times 100$, sendo $\mathrm{B}$ o número de negativos detectados no teste $\mathrm{e}(\mathrm{B}+\mathrm{D})$ o total de não doentes. 


\section{DISCUSSÃo}

Um parâmetro crítico para avaliação de novos testes de diagnóstico é a comparação dos resultados com dados obtidos a partir da técnica definida como padrão ouro. Todas as amostras submetidas a PCR foram também avaliadas por cultivo devido a elevada sensibilidade e especificidade da técnica, superior a 90\% em muitos trabalhos ${ }^{410}$. No entanto, algumas limitações da cultura são consideradas: 1) inviabilidade do bacilo após tratamento do escarro com lauril sulfato de sódio; 2) contaminação da cultura por outros microrganismos de crescimento rápido; 3 ) limite de sensibilidade de cerca de $10 \mathrm{UFC} / \mathrm{mL}$ de escarro.

Os resultados obtidos demonstram que não há diferença na sensibilidade para as técnicas de nested-PCR e cultura (Tabela 2). No entanto, em cinco casos de cultura positiva, sendo dois BAAR positivo e três BAAR negativo, a nested-PCR foi negativa. Esta observação pode ser devido à presença de inibidores da PCR, quantidade insuficiente de DNA ou ainda ausência do marcador molecular na população de bacilos investigada. Um dos pontos críticos para o uso da PCR como ferramenta diagnóstica é a obtenção do DNA, pois alguns espécimes clínicos podem conter substâncias inibidoras da PCR. Em alguns casos estes inibidores podem ainda ser inseridos durante a manipulação do material genético.

Cinco por cento dos espécimes clínicos avaliados por AnjosFilho cols ${ }^{1}$ continham inibidores de PCR e foram responsáveis por seis dos nove resultados falso-negativos encontrados. Neste trabalho, o procedimento de obtenção do DNA micobacteriano utilizado envolveu várias etapas para purificação do DNA, entretanto, diversas foram as possibilidades de perda deste, tais como: 1) escolha da porção mais adequada do escarro a ser trabalhada, 2) perda durante a transferência da fração aquosa após partição em líquidos imiscíveis, 3) centrifugação inadequada, 4) lavagens excessivas, 5) secagem prolongada. Outra situação que poderia justificar o resultado negativo para PCR e positivo para cultura seria a ausência do marcador molecular investigado em um percentual dos agentes etiológicos. Porém, as cinco cepas isoladas por cultivo apresentaram amplificação para o gene codificante do antígeno $\mathrm{B}$, após uso dos mesmos iniciadores utilizados na reação a partir do escarro. Suffys cols ${ }^{13}$ ao avaliarem a PCR como ferramenta para o diagnóstico da tuberculose pulmonar por meio da amplificação de uma região de 178pb da sequiência de inserção IS6110 do M. tuberculosis relataram positividade em apenas $44 \%$ dos casos com diagnóstico clínico e radiológico de tuberculose. A baixa sensibilidade foi justificada pela introdução de substâncias inibidoras durante 0 procedimento de extração com sílica-guanidina tiocianato.

A lavagem exaustiva do DNA obtido de escarro para eliminação de substâncias inibidoras da enzima DNA polimerase é fortemente recomendada ${ }^{2}$. Uma estratégia para verificar a presença de substâncias inibidoras da PCR seria acrescentar oligonucleotídeos iniciadores universais na reação em análise e em uma reação em separado. A observação de amplificação referente ao fragmento dos oligonucleotídeos universais em ambas as reações afastaria a hipótese de inibidores. 0 mesmo procedimento poderia ser feito usando concentrações variadas de DNA do controle positivo.
Uma variedade de marcadores moleculares tem sido investigada em sua aplicabilidade para diagnóstico da tuberculose ${ }^{2511}$. Diferentes sequiências alvo para PCR como IS6110, genes condificantes de proteínas como a de $65 \mathrm{kDa}$ ou $38 \mathrm{kDa}$ e MPB64 foram relatadas em $100 \%$ das 57 cepas de M. tuberculosis identificadas no Estado do Amazonas. Os autores relatam que em amostras clínicas multibacilares, apenas a sequiência MPB64 não apresentou $100 \%$ de eficácia para diagnóstico da tuberculose, sendo observado $89 \%$ de detecção dos casos positivos. Entre as amostras paucibacilares a co-positividade foi variada, no entanto, o fragmento de 123pb do alvo IS6110 apresentou 95\% de co-positividade com a cultura, resultado superior aos demais marcadores, incluindo o gene da proteína de 38kDa (91\%) avaliado naquele estudo ${ }^{11}$. Para Ogusku \& Salem (2004) a maior eficácia da sequiência IS6110 para o diagnóstico da tuberculose em relação ao gene codificante da proteína $38 \mathrm{kDa}$ pode estar associada ao fato de 0 primeiro estar presente em múltiplas cópias no genoma do M. tuberculosis (5 a 19 cópias).

Resultados positivos para nested-PCR foram observados em dois casos confirmados clinicamente como tuberculose apesar dos resultados inconclusivos de cultura para M. tuberculosis. Um destes casos é referente a uma amostra que contaminou por crescimento de fungo, mas foi positiva na baciloscopia. Na outra amostra foi observado crescimento de micobactéria não tuberculosa no primeiro cultivo e ausência de crescimento micobacteriano após duas novas coletas. Neste último caso, o paciente foi notificado após resultado da primeira baciloscopia classificada como três cruzes $(+++)$ e reativo no PPD. Dois meses depois o paciente foi re-avaliado clinica e laboratorialmente, sendo mantido como caso de tuberculose. É possível que a cultura negativa tenha sido decorrente da ausência de bacilos viáveis, pois a segunda coleta foi realizada um mês após introdução da terapêutica. Ambos os casos foram considerados como tuberculose, inicialmente por apresentarem sintomas característicos (tosse produtiva a mais de um mês, emagrecimento, febre noturna, cansaço), reatividade para o PPD, positividade para BAAR e posteriormente a melhora clínica após introdução da terapia.

Amplificações do fragmento de $322 \mathrm{pb}$ foram observadas em 12 amostras provenientes de casos não diagnosticados como tuberculose. Esta situação pode ser atribuída a: 1) contaminação dos espécimes com DNA; 2) contaminação de reagentes e instrumentos com DNA ou amplicons resultantes da primeira reação; 3) presença de organismos não viáveis em pacientes. É importante relatar que todos os procedimentos de extração realizados para este trabalho foram acompanhados por controle negativo (amostra de escarro com resultado negativo em cultura e PCR) que não amplificaram nas reações de PCR, no entanto, estes controles, eram normalmente manipulados antes das amostras testes ou controles positivos (o que impossibilitava a deteç̧ão de falha técnica por contaminação do controle negativo após a pipetagem de amplicons). Uma boa alternativa é estabelecer nos protocolos de laboratório o desenvolvimento de pelo menos três controles negativos, com manipulação a cada cinco ou dez amostras teste, dependendo da rotina de trabalho. Deixando 
claro que o controle negativo não deve ser restrito a adição de água na reação de PCR, mas a uma amostra que sofreu todos os procedimentos das amostras testadas para o diagnóstico. Todos os 12 pacientes cujos resultados laboratoriais foram negativos na bacilospia e cultura e positivos na PCR foram consultados quanto à notificação de tuberculose em outros períodos. Nenhum paciente apresentou registro no SINAN até a data de 22 de maio de 2006.

Resultados preliminares obtidos em nosso laboratório evidenciam PCR positivo e cultura negativa em $50 \%$ dos casos de acompanhamento de pacientes após alta de tuberculose por cura (dados não apresentados). No entanto, em nenhum dos casos de cultura negativa e nested-PCR positivo foi relatado tratamento anterior ou história de contato com paciente infectado pelo M. tuberculosis, o que poderia sugerir presença de DNA de M. tuberculosis nos indivíduos investigados.

Os resultados apresentados demonstram a PCR como uma técnica rápida para detecção de sequiência genômica característica do $M$. tuberculosis, apresentando sensibilidade equivalente à cultura, com a facilidade de diferenciar cepas do complexo M. tuberculosis de outras. No entanto, precisa ser melhor avaliada, de forma a minimizar o número de resultados falso-positivos e, então, ser aplicada como ferramenta complementar a outros métodos diagnóstico, inicialmente em Laboratórios de Referência.

\section{AGRADECIMENTOS}

Às técnicas Ivanilda Santabrígida e Natália Rodrigues Marques pelo gerenciamento e transporte dos espécimes clínicos da Unidade de Saúde do Marco ao Laboratório de Tuberculose do Instituto Evandro Chagas.

\section{REFERÊNCIAS}

1. Anjos-Filho L, Oelemann WMR, Barreto CEN, Kritski AL, Fonseca LS. Sensitivity of amplicor MTB on direct detection of Mycobacterium tuberculosis in smear- negative specimens from outpatients in Rio de Janeiro. Brazilian Journal of Microbiology 33: 163-165, 2002.

2. Bollela VR, Sato DN, Fonseca BAL. Problemas na padronização da reação em cadeia da polimerase para diagnóstico da tuberculose pulmonar. Revista de Saúde Pública 33: 281-286, 1999.

3. Fundação Nacional de Saúde. Manual de Bacteriologia da Tuberculose. Centro de Referência Professor Hélio Fraga, Ministério da Saúde, Rio de Janeiro, 1994.

4. Gordin F, Slutkin G. The validity of acid-fast smears in the diagnosis of pulmonary tuberculosis. Archives of Pathology and Laboratory Medicine 114: 1025-1027, 1990.

5. Kox LFF, Rhienthong D, Miranda AM, Udomsantisuk N, Ellis K, van Leeuwen J, van Heusden S, Kuijper S, Kolk AHJ. A more reliable PCR for detection of Mycobacterium tuberculosis in clinical samples. Journal of Clinical Microbiology 32: 672-678, 1994.

6. Lopes ML, Lima KVB, Cardoso NC, Rodrigues N, Loureiro ECB. Situação epidemiológica da tuberculose em unidade de referência para o estado do Pará. In: Resumos do I Encontro Nacional Sobre Tuberculose, Brasília p. 13-12, 2004.

7. Martins LC, Paschoal IA, Nowakonski AV, Silva SAB, Costa FF, Ward LS. Nested-PCR using MPB64 fragment improves the diagnosis of pleural and meningeal tuberculosis. Revista da Sociedade Brasileira de Medicina Tropical 33: 253-257, 2000.

8. Ministério da Saúde. Análise da situação da tuberculose no Brasil. In: Saúde Brasil 2005: uma análise da situação de saúde no Brasil. Departamento de análise de situação em saúde. Secretaria de Vigilância em Saúde, Brasília, p. 721-753, 2005.

9. Miyazaki Y, Yoga H, Kohno S, Kaku M. Nested polymerase chain reaction for detection of Mycobacterium tuberculosis in clinical samples. Journal of Clinical Microbiology 31: 2228-2232, 1993.

10. Noordhoek GT, Kaan JA, Mulder S, Wilke H, Kolk AHJ. Application of the polymerase chain reaction in a routine microbiology laboratory for detection of Mycobacterium tuberculosis in clinical samples. Journal of Clinical Pathology 48: 810-814, 1995.

11. Ogusku MM, Salem JI. Análise de diferentes primers utilizados na PCR visando diagnóstico da tuberculose no Estado do Amazonas. Jornal Brasileiro de Pneumologia 30: 343-349, 2004.

12. Sarmiento OL, Weigle KA, Alexander J, Weber DJ, Miller WC. Assessment by metaanalysis of PCR for diagnosis of smear-negative pulmonary tuberculosis. Journal of Clinical Microbiology 41: 3233-3240, 2003.

13. Suffys P, Vanderborght PR, Santos PB, Correa LAP, Bravin Y, Kritski AL. Inhibition of the polymerase chain reaction by sputum samples from tuberculosis patients after processing using a silica- guanidiniumthiocyanate DNA isolation procedure. Memórias do Instituto Oswaldo Cruz 96: 1137-1139, 2001. 